\title{
Development of a Methodology for Structural and Mechanical Characterization of Extended Sheets Made from Stainless Steels
}

\author{
Geraldo Lúcio de Faria ${ }^{a *}$, Leonardo Barbosa Godefroid ${ }^{a}$, Victor Silva Menezes ${ }^{a}$ \\ ${ }^{a}$ Universidade Federal de Ouro Preto - UFOP, Campus Universitário do Morro do Cruzeiro, \\ Ouro Preto, MG, Brazil
}

Received: November 7, 2014; Revised: July 28, 2015

\begin{abstract}
Extended sheets are produced by a pressure cutting process to transform common sheets in expanded metal. These sheets are usually made of carbon steel, but due to their corrosion susceptible, studies have been developed with the aim to evaluate the viability of replacing these common steels by stainless steels. This study proposed an experimental method to characterize structural and mechanically samples of stainless steel extended sheets (410D, 444A, 439 and 304A) and a 1010 carbon steel sheet thicker than the others. This study has a practical importance because nowadays there are not standardized procedures to do this kind of evaluation. The obtained results showed that the methodology was effective for the proposed objective and that the expanded sheets made of stainless steels have a better performance in terms of mechanical strength compared to the 1010 steel sheet.
\end{abstract}

Keywords: extended sheets, stainless steels, microstructural and mechanical characterization

\section{Introduction}

In any kind of industry, especially sugar and oil ones, operational stops for equipment maintenance are prejudicial to a high productive plant. The costs associated to the pieces of equipments and structural components replacement, as the time of production interruption, is main factors that affect their yield ${ }^{1-3}$.

Usually, the equipment and metal structures are subjected to mechanical loads and aggressive environments. For this reason, parts made of carbon steel fail and need to be replaced frequently. In this context, the use of stainless steel in the production of some components has been established as an important alternative to promote the specific corrosion loss decreasing ${ }^{1-5}$.

Nowadays, an important application for stainless steels is the development of extended sheets that are often used in the sugar and oil plants under aggressive environments. There are few studies about this subject. The extended sheet consists of steel sheets that are submitted to cutting procedures and mechanical strain, being transformed into a rigid and uniform one-piece web. The extended sheets can be used in various applications including: railings, gates, equipment protection, filters, floors, stairs, railings, pipes and gutters, ceilings and linings in construction, among others ${ }^{1,2}$.

The extended sheets for more robust applications are mostly manufactured of carbon steels such as AISI 1010 or AISI 1020. Through the years, this material selection has been defined only in terms of attendance of mechanical properties requirements and raw material costs. However, studies have shown that in a medium and long period, the number of events with production interruption for maintenance and replacement of sheets made of carbon steels have a great contribution on the cost/gain rate. Those stops increase

*e-mail: geraldolfaria@yahoo.com.br especially in sectors such as sugar and oil production, where these sheets work under extremely aggressive conditions (corrosion, high temperatures and pressures, high levels of mechanical stress, mechanical vibrations, etc. $)^{1,2,6}$. In this context, the class of stainless steels is a potential candidate for the substitution of carbon steel in applications involving the use of extended sheets of high mechanical strength in corrosive environments.

This study aimed to propose an experimental methodology to compare the structural and mechanical characteristics of extended sheets made of 410D, 444A, 439, 304A stainless steels, all with thickness of $4.5 \mathrm{~mm}$, with the AISI 1010 extended sheet, with a thickness of $5.5 \mathrm{~mm}$. If reducing the thickness of the stainless steel sheets has no negative influence on their mechanical behaviour when compared to carbon steel, this may be a solution to reduce the specific cost of the product manufactured in stainless steel.

According to the literature, the use of 410D stainless steels is suitable when the application of materials requires abrasive and non-corrosive applications, especially in humid environments (like what happens in alcohol and sugar industries) $)^{1,2,4}$.

The 444A stainless steel has a chemical constitution, which ensures that the passive layer remains stable facing in reducing environments where chloride ion is present. According to the literature, this property is attributed mainly to the addition of molybdenum and a high content of chromium. In this context, this material is used in equipments such as heaters, evaporators, vacuum cookers, crystallizers and dryers in the sugar industry ${ }^{5-13}$.

The ferritic stainless steel 439 has a good oxidation resistance and due to the presence of $\mathrm{Nb}$ and $\mathrm{Ti}$, it has low susceptibility to intergranular corrosion. 
The 304A stainless steel has a good ductility, good resistance to stress-corrosion in environments containing chloride, good resistance to pitting corrosion and is hardenable by mechanical forming ${ }^{13-17}$.

As there are no international standards accepted for mechanical tests on extended sheets, this work has a original character, regarding the experimental methodology and the fact that it presents the possibility of materials substitution in extended sheet manufacturing.

\section{Material and Methods}

\subsection{Materials}

Extended sheets made of 410D, 444A, 439 and 304A stainless steel and 1010 carbon steel were studied. The chemical composition of the materials is shown in Table 1. It is observed that, in general, all the steels have low carbon content. It is remarkable that the $410 \mathrm{D}$ steel has the lowest $\mathrm{Cr}$ content and the 304A has the highest $\mathrm{Ni}$ content ( $\gamma$-gene element) compared to the other stainless steels. It is also noted a significant amount of $\mathrm{Ti}$ in 444A and 439 steels which is a carbonitride forming element ${ }^{11,13,15}$.

The extended sheets were cut with reduced dimensions for this work. Figure 1 shows an example of a sample in the as received condition. Extended sheets fabricated from stainless steel were produced with a thickness of $4.5 \mathrm{~mm}$ and the ones fabricated from carbon steel with a thickness of $5.5 \mathrm{~mm}$.

\subsection{Experimental procedures}

Initially the extended sheets were microstructurally characterized by optical microscopy. Two areas were analysed: rods, i.e., regions that has a smaller width and the longest length, and joints, i.e., regions of intersection of two rods. All the areas were analysed in three surfaces, which were divided as superficial, longitudinal and transversal.
The surfaces were submitted to standard metallographic procedures (ASTM E3-11) ${ }^{18}$ and analysed before the etching with the aid of the EDS technique in a scanning electron microscope JEOL JSM 5510, to chemically characterize inclusions in steels.

Samples of the extended sheets were etched and the resultant microstructure of the mechanical forming process was revealed and analysed on an Olympus optical microscope equipped with an image analyser. The used etching procedures are shown in Table 2.

Aiming to mechanically characterize the extended sheets and compare the performance of those made of stainless steels, with thickness of $4.5 \mathrm{~mm}$, and made of carbon steel, with thickness of $5.5 \mathrm{~mm}$, an experimental methodology was proposed, since there are no standardized procedures well established for this purpose. This methodology was based on hardness, tensile and bending tests.

Initially, ten measurements of Vickers hardness were performed in each sample, on joints and rods. An Otto Wolpert-Werke hardness tester was used. The applied load was $30 \mathrm{kgf}$ with an application time of $30 \mathrm{~s}$.

Since there are no standards for tensile tests on extended sheets, this study has proposed to use five specimens for each steel type. The five specimens were tested, but only three were validated aiming to calculate representative average values for evaluated properties and to obtain a restrict experimental

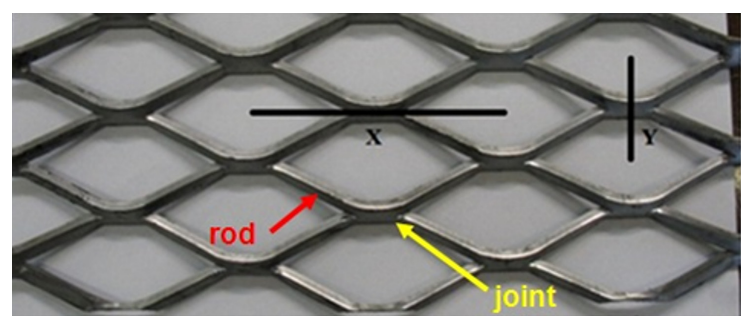

Figure 1. Geometric aspect of the samples of extended sheets in the as received condition $(\mathrm{x}=100 \mathrm{~mm}, \mathrm{y}=41 \mathrm{~mm})$.

Table 1. Chemical composition of the studied steels ( $\mathrm{wt} \%$ ).

\begin{tabular}{|c|c|c|c|c|c|c|c|c|c|}
\hline & C & Mn & Si & $\mathbf{P}$ & $\mathbf{S}$ & $\mathrm{Cr}$ & $\mathbf{N i}$ & Мo & Al \\
\hline $410 \mathrm{D}$ & 0.007 & 0.58 & 0.57 & 0.022 & 0.0005 & 11.28 & 0.338 & 0.0065 & 0.002 \\
\hline $444 \mathrm{~A}$ & 0.009 & 0.53 & 0.53 & 0.021 & 0.0006 & 17.51 & 0.249 & 1.7908 & 0.005 \\
\hline 439 & 0.014 & 0.14 & 0.59 & 0.024 & 0.0002 & 17.11 & 0.234 & 0.0140 & 0.005 \\
\hline $304 \mathrm{~A}$ & 0.045 & 1.17 & 0.43 & 0.031 & 0.0012 & 18.15 & 8.027 & 0.0658 & 0.003 \\
\hline \multirow[t]{2}{*}{1010} & 0.090 & 0.47 & 0.01 & 0.015 & 0.0177 & 0.013 & 0.008 & 0.0018 & 0.045 \\
\hline & $\mathrm{Cu}$ & $\mathbf{V}$ & $\mathbf{N b}$ & $\mathbf{T i}$ & $\mathbf{N}_{2}(\mathbf{p p m})$ & & & & \\
\hline 410D & 0.029 & 0.033 & 0.017 & 0.003 & 134 & & & & \\
\hline $444 \mathrm{~A}$ & 0.038 & 0.046 & 0.164 & 0.162 & 116 & & & & \\
\hline 439 & 0.024 & 0.036 & 0.170 & 0.194 & 102 & & & & \\
\hline $304 \mathrm{~A}$ & 0.104 & 0.046 & 0.004 & 0.004 & 457 & & & & \\
\hline 1010 & 0.010 & 0.0001 & 0.002 & 0.001 & - & & & & \\
\hline
\end{tabular}

Table 2. Etching techniques applied to reveal microstructures.

\begin{tabular}{cl}
\hline Steels & Etching Procedures \\
\hline $410 \mathrm{D}, 444 \mathrm{~A}$ and 439 & Villela $(2 \mathrm{~g}$ of picric acid, $100 \mathrm{ml}$ of ethanol e $5 \mathrm{ml}$ of hydrochloric acid - 20 seconds $)$ \\
$304 \mathrm{~A}$ & $5 \mathrm{ml}$ of glycerin, $15 \mathrm{ml}$ of hydrochloric acid, $10 \mathrm{ml}$ of nitric acid and $10 \mathrm{ml}$ of acetic acid - $25 \mathrm{~seconds}$ \\
1010 & Nital $2 \%(98 \%$ of ethanol and $2 \%$ of nitric acid - 5 seconds $)$ \\
\hline
\end{tabular}




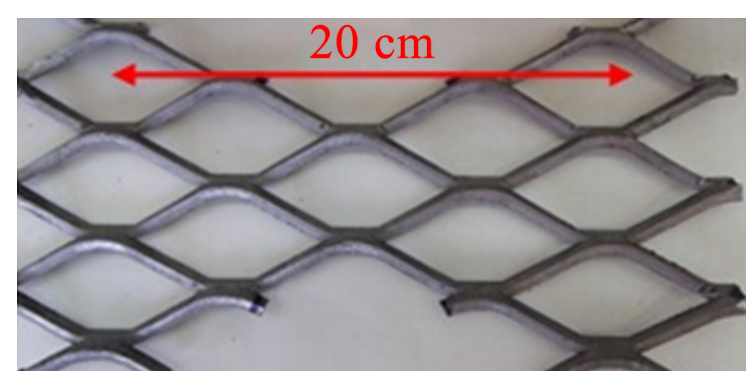

Figure 2. Proposed specimen for tensile test in extended sheets.

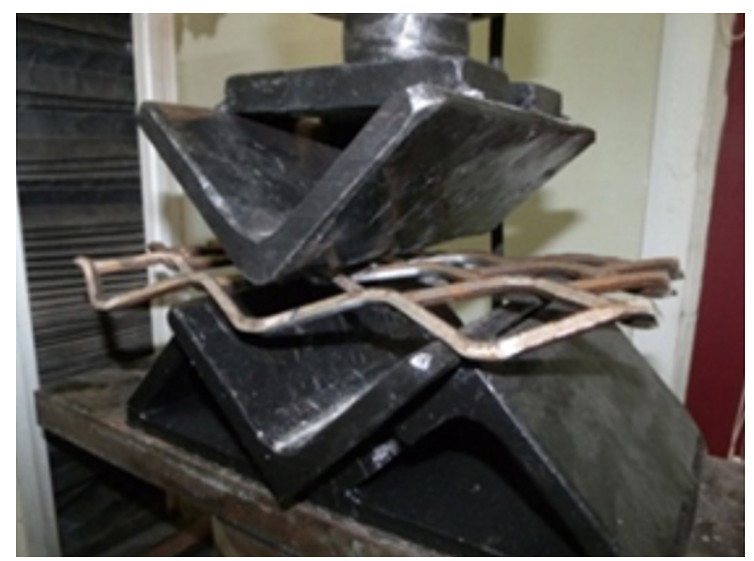

Figure 3. Developed device for bending test on extended sheets $\left(90^{\circ}\right)$.

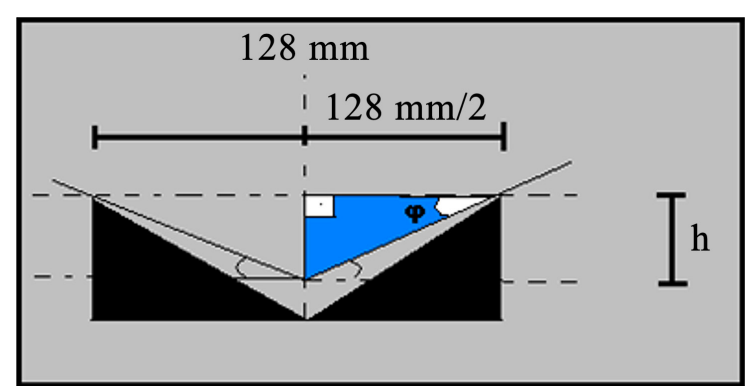

Figure 4. Schematic figure illustrating the geometrical construction used to calculate the bending angle as a function of displacement of the upper punch. error. The specimens were cut in order to standardize their geometry. Figure 2 shows a standard specimen proposed. The other dimensions, such as rod thicknesses and hole sizes, were left unchanged.

Due to the complex geometry of the extended sheets, the procedures of measurement of their cross-sectional areas, in real-time during the test, were a hard and a very imprecise operation. In this context it was decided to register and work with load-elongation data (replacing tension-strain data) until the sample fracture. Each one of the samples tested in tensile test was submitted to fractographic analysis in a scanning electron microscope FEI Inspect 550.

For bending tests, a device for bending in $90^{\circ}$ was adapted to a Kratos universal testing machine with the maximum load capacity of 10tons. Figure 3 shows the developed device for bending tests on extended sheets.

The geometric relations that provided the relationship between the bending angle and the upper mandrel displacement (h) (Equation 1) are shown in the Figure 4. By means of this assembly it was possible to obtain the load (F) versus bending angle $(\theta)$ curves.

$$
\theta=2 \times \tan ^{-1} \frac{2 \times h}{128}
$$

After bending at $90^{\circ}$, the samples were inspected and analysed aiming to verify the presence or absence of defects. Samples bent in $90^{\circ}$ were then tested in bending until $180^{\circ}$ in an Amsler universal testing machine. The samples were again inspected to check the presence or absence of defects.

\section{Results and Discussion}

\subsection{Microstructural characterization}

Figure 5 presents the microstructures of transversal sections of the joints and rods for all studied sheets. Although the other sections have been examined, only the images in this section were presented because it was where the biggest microstructural difference was observed due to the plastic strain during the manufacturing process.

It is observed that the $1010,439,444 \mathrm{~A}$ and $410 \mathrm{D}$ steels, have predominantly ferritic microstructure, as expected ${ }^{8-16}$. However, there is a significant difference in the morphology

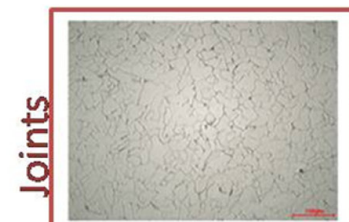

(a)

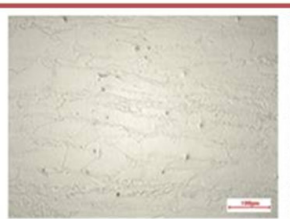

(b)

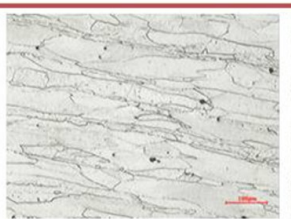

(c)

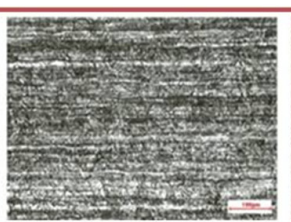

(d)

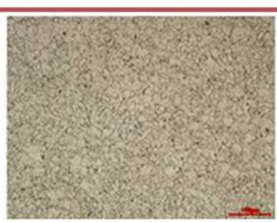

(e)

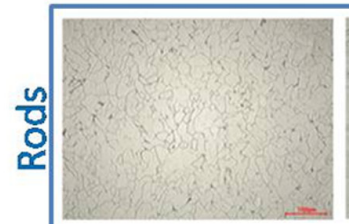

(a)

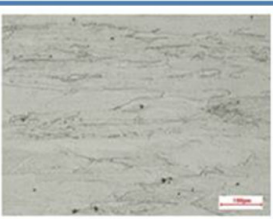

(b)

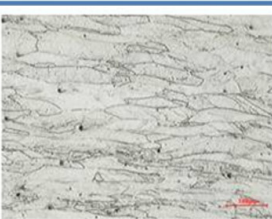

(c)

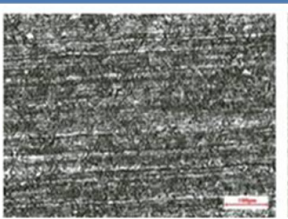

(d)

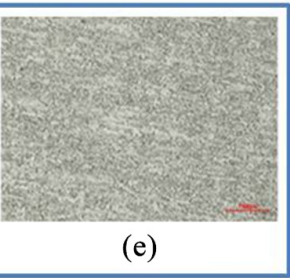

Figure 5. Microstructure of extended sheets on transversal section of rod and joint areas (a) 1010 (b) 439 (c) 444A (d) 304A (e) 410D. 
and the average grain size. The 1010 carbon steel presented, in both joints and rods, equiaxial grains, inferring that this sheet was probably recrystallized before its expansion. The other samples presented elongated grains, the rods being the part of the component with highest anisotropic aspect. With respect to the ferritic stainless steels, the structures with larger grain sizes were of the 439 and 444A.

The 304A stainless steel had a complex austenitic microstructure, strongly strain hardened, which is in accordance with the literature ${ }^{14,15,17}$. It is observed a high density of slip lines and twinned regions that darken the etched microstructure.

The 1010 carbon steel presented globular oxide inclusions. The 444A and 439 ferritic stainless steels had titanium nitrides and the 304A austenitic stainless steel, chromium nitrides, in accordance with the literature ${ }^{13,16}$. Figure 6 shows secondary electron images (SEM) and the collected spectra (EDS) confirming the chemical composition of these inclusions.

\subsection{Mechanical characterization}

Figure 7 shows Vickers hardness results of all studied extended sheets. The measurements were made at the joints and rods. It is possible to note that, for all materials, the rod hardness is higher than the joints one. This can be explained because during the sheet expansion process the joint is the most plastic strained region and therefore more strain hardened.

Among the studied steels, it is possible to see that the highest hardness is on the rod of the 304A steel, in accordance with the literature ${ }^{17}$, that affirms 304A stainless steel has a higher strain hardening susceptibility. The ferritic stainless steels (410D, 444A and 439) presented hardness values around 170 and $190 \mathrm{HV}$ at the joints and between 190 and 220HV at the rods. The lowest hardness is at joint of the 1010 steel.

Figure 8a presents the load-displacement curves obtained in tensile tests for all the extended sheets. Two nearly linear regimes could be observed during the tests. In the first, the
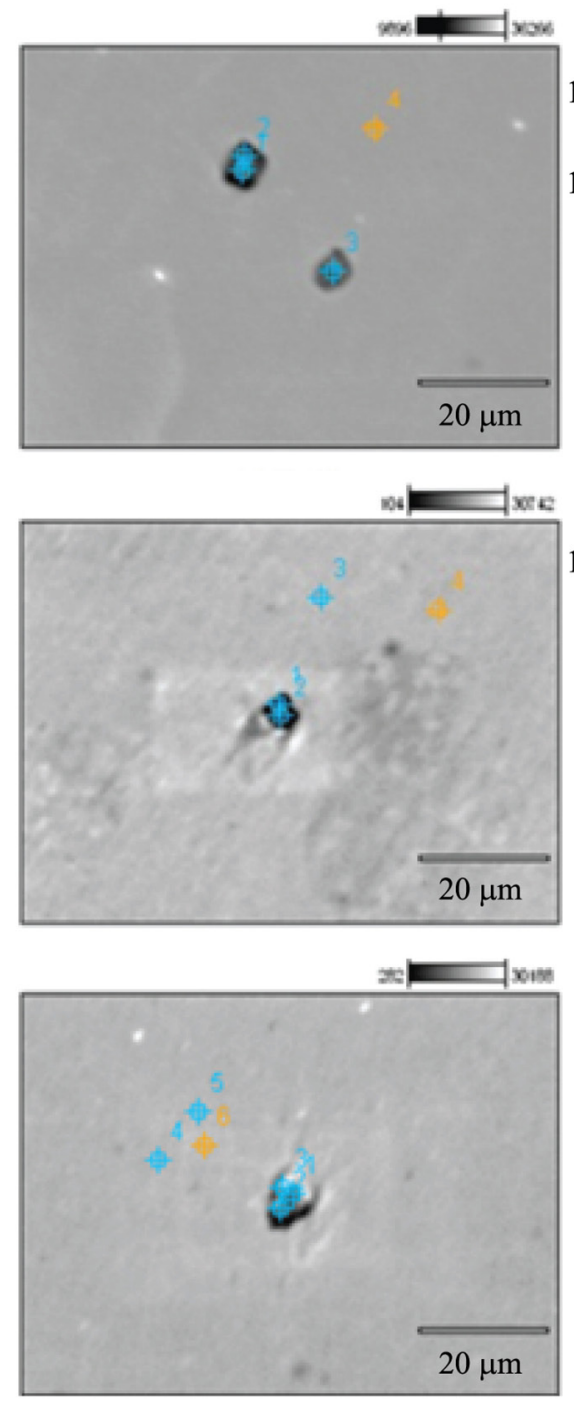
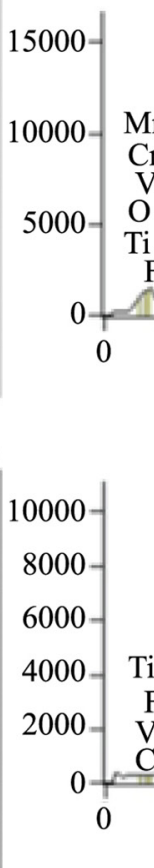

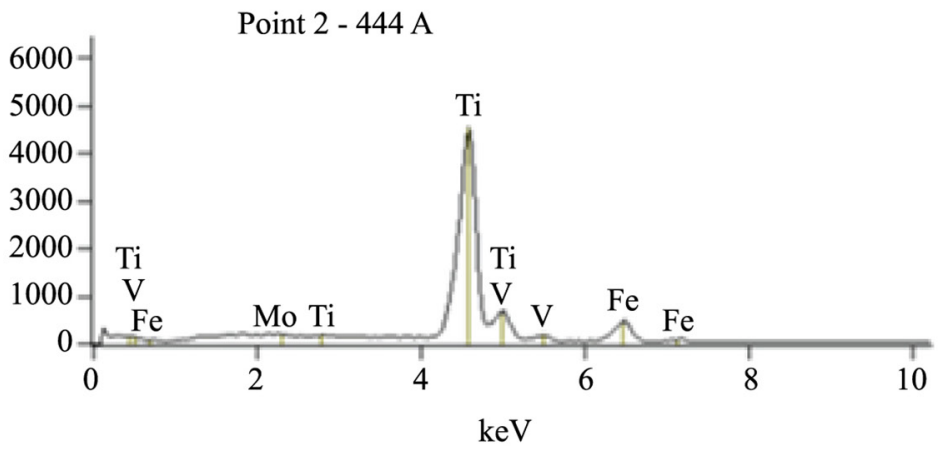

Point 3 - 304 A

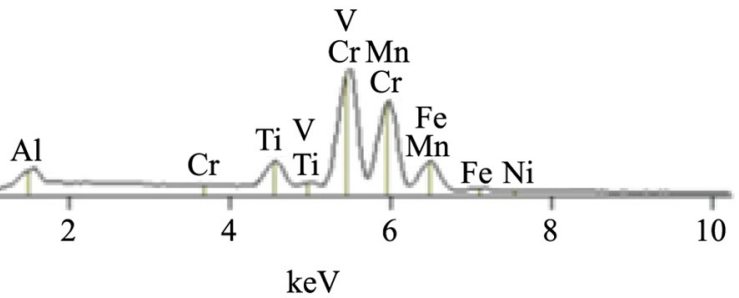

Point 1 - 439

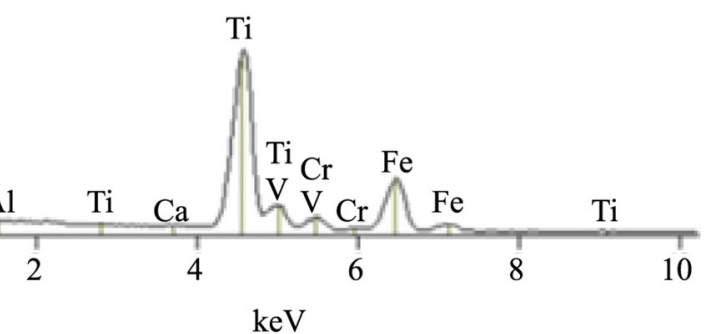

Point 2 - 444 A

Figure 6. Chemical analysis of inclusions in 304A, 439 and 444A steels (EDS). 
load increases at a high rate, almost constant, as the sheets deform elastically and after with the process of trusses closing, approaching adjacent joints. From a certain value of load, the load growth rate decreased and provided the end of the truss closing and the continuance of the rods plastic strain until the failure. The failure occurred mainly at the intersection of the rods and the joints, which is a point of high stress concentration in this type of product.

It can be seen that the 304A steel has higher mechanical strength to the start of the truss closing $(2750 \mathrm{kgf})$ followed by the 444A steel (1800kgf) and the 410D (1900kgf). The worst

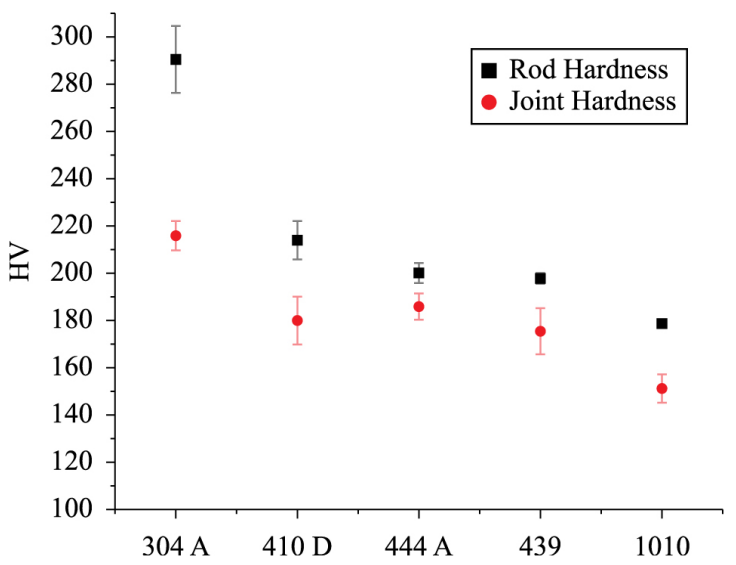

Figure 7. Vickers hardness measured at extended sheet rods and joints.

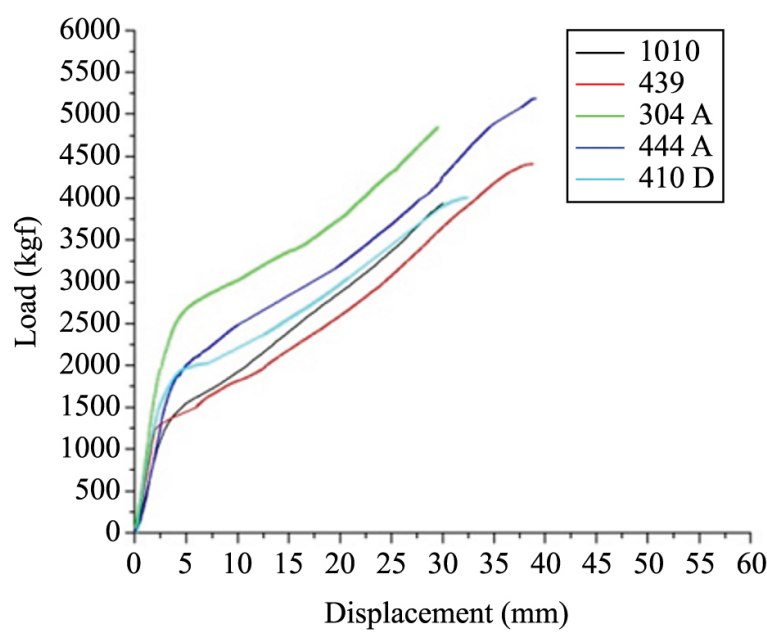

(a) performances, in terms of resistance to the truss closing, were the 439 (1250kgf) and the 1010 (1350kgf) steels. According to the literature, these stainless steels, disregarding the effect of strain hardening, have yield strengths in ascending order as 444A, 410D, 304A and 439, but when the 304A is strain hardened it can reach higher yield strength than the $444 \mathrm{~A}$ steel ${ }^{1,2}$. Therefore, it can be seen that the mechanical behaviour of the extended sheets under tension (proposed test) are coherent with the nominal properties of steels.

Figure $8 \mathrm{~b}$ shows that the area reduction of the 410D steel was the lowest. The association of its small grain size with its significant strain hardening can explain this behavior. The second lowest area reduction was presented by the 304A steel, which has many regions of twinning as well a high density of slip lines. For both cases, the high density of favourable points for microvoids nucleation during plastic strain and the small size of dimples, explain the low area reduction. The others ferritic steels, which have grains with low strain level, presented a similar average area reductions, between 50 and $55 \%$.

Figure 9 shows microfractographies of tensile test specimens. It can be seen that the fracture mechanisms of all the studied steels is nucleation, growth and coalescence of microvoids. It can be observed that the steels which presented the lowest area reductions are precisely those with the smaller dimples sizes.

Figure 10a presents the quantitative results of the bending test at $90^{\circ}$, with data register until $60^{\circ}$ due to operational

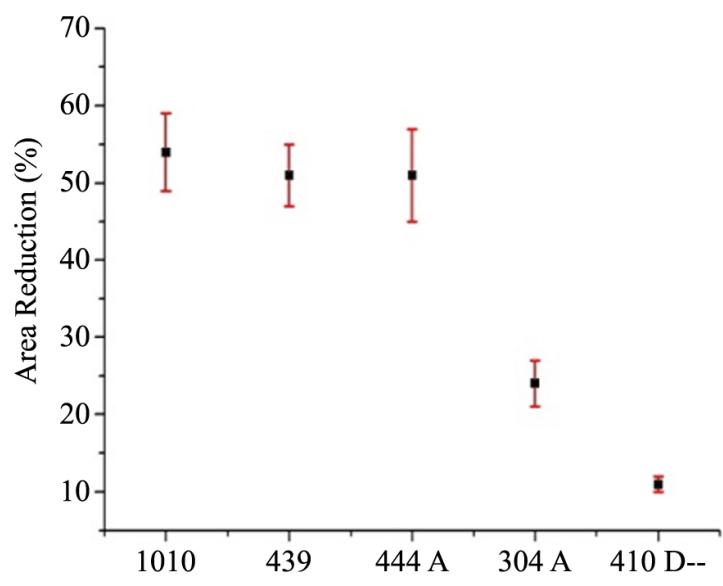

(b)

Figure 8. (a) Load versus displacement curve; (b) Area reduction data.

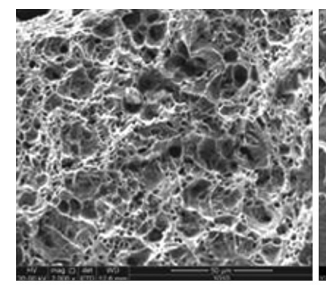

(a)

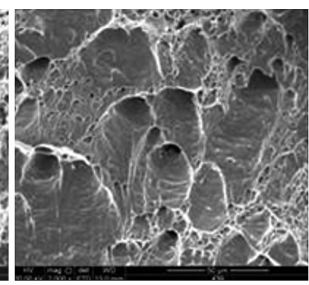

(b)

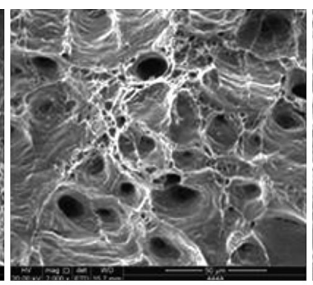

(c)

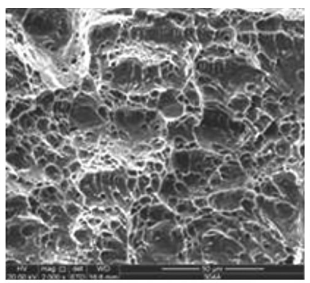

(d)

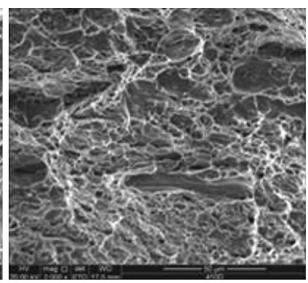

(e)

Figure 9. Microfractographic analysis of tensile test specimens (a) 1010 (b) 439 (c) 444A (d) 304A (e) 410D - 2000x SEM images. 


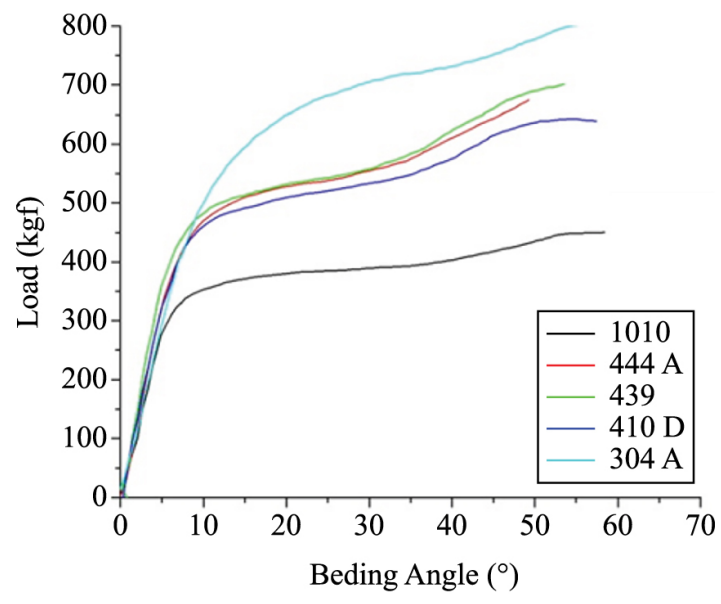

(a)

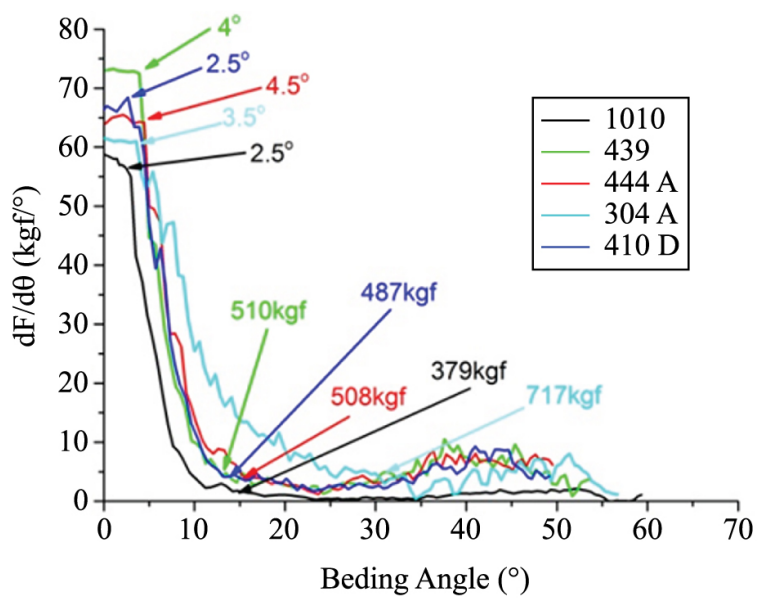

(b)

Figure 10. (a) Load versus bending angle curve. (b) Load increasing rate curve.

issues. After the bending tests at $90^{\circ}$, all samples were macroscopically evaluated and then bended until $180^{\circ}$. Figure $10 \mathrm{~b}$ presents the curve of load rate in relation to the bending angle. This curve was used to determine the highest supported loads before the continuous sheets bending under almost constant load. It is possible to observe that 1010 sheet has the lowest bending strength.

By means of these two curves, it can be said that the 304A steel has the highest resistance to bending while the 1010 steel the smallest. After bending at $180^{\circ}$, it was noted that the $304 \mathrm{~A}$ and $410 \mathrm{D}$ steels presented cracks in the intersection region between rods and joints, while others do not.

\section{Conclusions}

The proposed experimental methodology for the structural and mechanical characterization of the extended sheets was effective to achieve the objectives of this research.

\section{References}

1. Carbó HM. Stainless steel: aplications and specifications. Luxembourg: Arcelor Mittal; 2008.

2. Labiapari WS, Carvalho JAN, Andrade JR, Alcântra CM, Schmalz RC and Mello JDB. Consolidação de um novo produto: P410D para usinas sucroalcooleiras. Núcleo Inox. 2008; 30:299-307.

3. Durmoo S, Richard C, Beranger G and Moutia Y. Biocorrosion of stainless steel grade 304L (SS304L) in sugar cane juice. Electrochimica Acta. 2008; 54(1):74-79. http://dx.doi. org/10.1016/j.electacta.2008.06.028.

4. Cleiton CS, Hélio CM and Hosiberto BS and Jesualdo PF. Austenitic and ferritic stainless steel dissimilar weld metal evaluation for the applications as-coating in the petroleum processing equipment. Materials \& Design. 2013; 47:1-8. http://dx.doi.org/10.1016/j.matdes.2012.11.048.

5. Hua-bing L, Zhou-hua J, Zu-rui Z, Yang C and Yan Y. Intergranular corrosion behavior of high nitrogen austenitic stainless steel. International Journal of Minerals, Metals and Materials. 2009; 16(6):654-660.
The plastic strain of sheets, during their manufacture process, has a strong influence on sheet microstructures. It promotes the grains morphology change, with notable elongation in the strain direction. The strain hardened grains were observed predominantly on the rods area (highest hardness), and in a smaller proportion on the joints (smallest hardness).

It was concluded that despite the extended sheets made of the 1010 steel have a higher thickness than the others tested, their strength limits in tensile and bending tests were lower than those sheets made of stainless steel. Under the mechanical point of view, the extended sheets made of stainless steel with lowest thickness meet perfectly the quality requirements for this application.

\section{Acknowledgements}

Joner Oliveira Alves and APERAM South America for kindly providing materials for this study.

6. Elsariti SM and Haftirman. Behaviour of stress corrosion cracking of austenitic stainless steels in sodium chloride solutions. Procedia Engineering. 2013; 53:650-654. http:// dx.doi.org/10.1016/j.proeng.2013.02.084.

7. Faria GL, Alves JO and Godefroid LB. Chapas expandidas em aços inoxidáveis ferríticos. Revista do Aço. 2013; 10:30-33.

8. Tavares SSM, Souza JA, Herculano LFG, Abreu HFG and Souza CM Jr. Microstructural, magnetic and mechanical property changes in an AISI 444 stainless steel aged in the $560{ }^{\circ} \mathrm{C}$ to $800{ }^{\circ} \mathrm{C}$ range. Materials Characterization. 2008; 59(2):112116. http://dx.doi.org/10.1016/j.matchar.2006.11.002.

9. Han J, Li H and Xu H. Microalloying effects on microstructure and mechanical properties of $18 \mathrm{Cr}-2 \mathrm{Mo}$ ferritic stainless steel heavy plates. Materials \& Design. 2014; 58:518-526. http:// dx.doi.org/10.1016/j.matdes.2014.02.009.

10. Juuti T, Rovatti L, Mäkelä A, Karjalainen LP and Porter D. Influence of long heat treatments on the laves phase nucleation in a type 444 ferritic stainless steel. Journal of Alloys and Compounds. 2014; 616(15):250-256. http://dx.doi.org/10.1016/j. jallcom.2014.06.201. 
11. Han J, Li H, Zhu Z, Barbaro F, Jiang L, Xu H, et al. Microstructure and mechanical properties of friction stir welded $18 \mathrm{Cr}-2 \mathrm{Mo}$ ferritic stainless steel thick plate. Materials \& Design. 2014; 63:238-246. http://dx.doi.org/10.1016/j.matdes.2014.05.070.

12. Abreu HFG, Bruno ADS, Tavares SSM, Santos RP and Carvalho SS. Effect of high temperature annealing on texture and microstructure on an AISI-444 ferritic stainless steel. Materials Characterization. 2006; 57(4-5):342-347. http:// dx.doi.org/10.1016/j.matchar.2006.02.015.

13. Mathon MH, Perrut M, Poirier L, Ratti M, Hervé N and Carlan Y. Development of new ferritic alloys reinforced by nano titanium nitrides. Journal of Nuclear Materials. 2015; 456:449-454.

14. Sabioni ACS, Huntz AM, Luz EC, Mantel M and Haut C. Comparative study of high temperature behaviour in AISI 304 and AISI 439 stainless steels. Materials Research. 2003; 6(2):179185. http://dx.doi.org/10.1590/S1516-14392003000200012.
15. Huntz AM, Reckmann C, Haut C, Sévérac M, Herbst M, Resende F, et al. Oxidation of AISI 304 and AISI 439 Stainless Steels. Materials Science and Engineering A. 2007; 447(1-2):266-276. http://dx.doi.org/10.1016/j.msea.2006.10.022.

16. Lee KS, Yoon DH, Lee SE and Lee YS. The effect of thermomechanical treatment on the interface microstructure and local mechanical properties of roll bonded pure Ti/439 stainless steel multilayered materials. Procedia Engineering. 2011; 10:3459-3464. http://dx.doi.org/10.1016/j.proeng.2011.04.570.

17. Hanning F and Engelberg DL. Metallographic screening of grain boundary engineered type 304 austenitic stainless steel. Materials Characterization. 2014; 94:111-115. http://dx.doi. org/10.1016/j.matchar.2014.05.016.

18. American Society for Testing and Materials - ASTM. ASTM E3-11: standard guide for preparation of metallographic specimens. West Conshohocken; 2011. 